\title{
Higher intraindividual variability is associated with more forgetting and dedifferentiated memory functions in old age
}

\author{
Goran Papenberg a,*, Lars Bäckman ${ }^{\mathrm{b}}$, Christian Chicherio ${ }^{\mathrm{c}}$, Irene E. Nagel ${ }^{\mathrm{a}, \mathrm{d}}$, \\ Hauke R. Heekeren ${ }^{\mathrm{a}, \mathrm{d}}$, Ulman Lindenberger ${ }^{\mathrm{a}}$, Shu-Chen $\mathrm{Li}^{\mathrm{a}, *}$ \\ a Max Planck Institute for Human Development, D-14195 Berlin, Germany \\ ${ }^{\mathrm{b}}$ Aging Research Center, Karolinska Institute, S-17177 Stockholm, Sweden \\ ${ }^{c}$ Faculty of Psychology and Educational Sciences, University of Geneva, CH-1205 Geneva, Switzerland \\ d Department of Education and Psychology, Freie Universität Berlin, D-14195 Berlin, Germany
}

\section{A R T I C L E I N F O}

\section{Article history:}

Received 1 November 2010

Received in revised form 21 February 2011

Accepted 10 March 2011

Available online 1 April 2011

\section{Keywords:}

Performance variability

Forgetting

Episodic memory

Dedifferentiation

Dopamine

Aging

\begin{abstract}
A B S T R A C T
Intraindividual trial-to-trial reaction time (RT) variability is commonly found to be higher in clinical populations or life periods that are associated with impaired cognition. In the present study, higher within-person trial-to-trial RT variability in a perceptual speed task is related to more forgetting and dedifferentiation of memory functions in older adults (aged 60-71 years). More specifically, our study showed that individuals in a high-variability group $(n=175)$ forgot more memory scenes over a 1-week retention interval than individuals in the low-variability group $(n=174)$. In contrast, slower RT speed was associated with poorer episodic memory in general, but unrelated to the amount of forgetting. Moreover, results from multiple group latent factor analyses showed that episodic memory and working memory functions were more highly correlated in the high-variability $(r=.63)$ than in the low-variability $(r=.25)$ group. Given that deficits in dopamine (DA) modulation may underlie increases in RT variability, the present findings are in line with (i) recent animal studies implicating DA in long-term episodic memory consolidation and (ii) neurocomputational work linking DA modulation of performance variability to dedifferentiation of cognitive functions in old age.
\end{abstract}

(C) 2011 Elsevier Ltd. All rights reserved.

\section{Introduction}

A variety of clinical populations suffering from pathologies of the central nervous system are also characterized by increased trialto-trial reaction time (RT) variability (for reviews, see MacDonald, Li, \& Bäckman, 2009; MacDonald, Nyberg, \& Bäckman, 2006). Ample evidence has shown that trial-to-trial RT variability is greater in individuals with attention-deficit hyperactivity disorder (ADHD; e.g., Bellgrove, Hawi, Kirley, Gill, \& Robertson, 2005; Klein, Wendling, Huettner, Ruder, \& Peper, 2006; Vaurio, Simmonds, \& Mostofsky, 2009), schizophrenia (Manoach, 2003; Manoach et al., 2000), head injury (Hetherington, Stuss, \& Finlayson, 1996) and in populations with aging-related pathologies, such as mild cognitive impairment (Gorus, De Raedt, Lambert, Lemper, \& Mets, 2008; Strauss, Bielak, Bunce, Hunter, \& Hultsch, 2007), dementia (Gordon \& Carson, 1990; Hultsch, MacDonald, Hunter, Levy-Bencheton, \&

\footnotetext{
* Corresponding authors at: Center for Lifespan Psychology, Max Planck Institute for Human Development, Lentzeallee 94, 14195 Berlin, Germany. Tel.: +493082406 455; fax: +49308249939.

E-mail addresses: papenberg@mpib-berlin.mpg.de (G. Papenberg), shuchen@mpib-berlin.mpg.de (S.-C. Li).
}

Strauss, 2000; Knotek, Bayles, \& Kaszniak, 1990), and Parkinson's disease (de Frias, Dixon, Fisher, \& Camicioli, 2007). Moreover, healthy human aging is also associated with increasing RT variability (e.g., Li et al., 2004; Williams, Hultsch, Strauss, Hunter, \& Tannock, 2005) and such within-person variability has been shown to be predictive of longitudinal cognitive declines (Lövdén, Li, Shing, \& Lindenberger, 2007; MacDonald, Hultsch, \& Dixon, 2003). These findings together suggest that within-person variation in measures of cognitive speed is a behavioral indicator of neural integrity.

\subsection{Neuromodulation of intraindividual variability}

Conceivably, mechanisms underlying increased performance variability involve reduced brain resources at structural, functional, and neurochemical levels (MacDonald, Li, et al., 2009; MacDonald, Nyberg, et al., 2006). In this study, we focus on deficits in dopaminergic neuromodulation as a potential source of increased neural noise (Li, Lindenberger, \& Sikström, 2001; Servan-Schreiber, Printz, \& Cohen, 1990; Winterer \& Weinberger, 2004) that raise withinperson performance variability at the behavioral level. Several lines of evidence support the DA-variability link. First, neurocomputational theories have formally linked deficient dopaminergic neuromodulation to increased processing noise in neural net- 
works (e.g., Li \& Lindenberger, 1999; Li, Lindenberger, et al., 2001; Servan-Schreiber et al., 1990), subsequently resulting in higher performance variability. Second, investigating the cognitive phenotypic effects of the Catechol-O-Methyltransferase (COMT) gene, a study by Stefanis et al. (2005) showed that male Val/Val carriers of the COMT gene, whose prefrontal DA availability is lower due to faster enzymatic activity (Craddock, Owen, \& O'Donovan, 2006), exhibited higher intraindividual variability than Met/Met carriers. Third, direct empirical support for the DA-variability link comes from a recent receptor imaging study, which showed that lower DA D2 receptor binding in a number of extrastriatal regions was associated with increasing RT variability during recognition memory and executive performance (MacDonald, Cervenka, Farde, Nyberg, \& Bäckman, 2009). Forth, several clinical populations associated with increased variability (e.g., Parkinson's disease, ADHD, schizophrenia) are also characterized by faulty dopaminergic neurotransmission. Thus, both theory and data from different levels of analyses converge to suggest that individual differences in DA function are related to within-person variability.

\subsection{Interindividual differences in forgetting}

Research addressing the question of whether various individualdifference variables predict rates of forgetting has often reported invariant forgetting curves or yielded controversial results (for review, see MacDonald, Stigsdotter-Neely, Derwinger, \& Bäckman, 2006). Equivalent rates of forgetting have been shown for healthy controls and Alzheimer's disease patients (e.g., Christensen, Kopelman, Stanhope, Lorentz, \& Owen, 1998; Kopelman, 1985, 1992) as well as patients with diencephalic and medial-temporal lobe amnesia (McKee \& Squire, 1992). In aging research, forgetting rates have been studied across different age groups and retention intervals and the findings are mixed. Whereas some studies reported differences in initial performance, but invariant forgetting rates in older and younger adults (Fjell et al., 2005; Rybarczyk, Hart, \& Harkins, 1987; Spikman, Berg, \& Deelman, 1995), others have shown greater forgetting in older adults, especially after long delays (e.g., 1 week; see Huppert \& Kopelman, 1989; Park, Royal, Dudley, \& Morrell, 1988), or when testing individuals on episodic recall, rather than recognition tasks (MacDonald, Stigsdotter-Neely, et al., 2006). With respect to experimental manipulations, encoding factors such as meaningfulness of the material (Underwood \& Richardson, 1956), degree of learning (Slamecka \& McElree, 1983), and pictorial elaboration (Forbes \& Reese, 1974) have been found to affect initial rate of learning, but not rate of forgetting.

To date, however, no study has investigated whether individual differences in within-person trial-to-trial RT variability would be predictive of forgetting. This question is interesting in light of accumulating evidence suggesting that the DA system is involved in long-term memory formation and consolidation (e.g., Cervenka, Bäckman, Cselényi, Halldin, \& Farde, 2008; see Düzel et al., 2010 for review; Lisman \& Grace, 2005). Specifically, evidence from animal studies shows that DA antagonist infusion in the hippocampus results in larger memory deficits after longer as compared to shorter retention intervals (Bethus, Tse, \& Morris, 2010; O'Carroll, Martin, Sandin, Frenguelli, \& Morris, 2006). Bethus et al. (2010) found that, whereas a DA antagonist impaired long-term memory after $24 \mathrm{~h}$ of retention, it did not affect short-term memory retrieval 30 min after encoding. Furthermore, in humans there is recent evidence for a direct relation between lower DA D2 receptor binding in hippocampus and higher performance variability during recognition memory (MacDonald, Cervenka, et al., 2009). Accordingly, we hypothesize that, relative to individuals with lower withinperson variations, individuals with higher performance variability may forget more information, reflecting suboptimal DA neuromodulation.

\subsection{Variability and dedifferentiation of cognitive functions}

In addition to investigating whether RT variability predicts rate of forgetting, the present study focuses on another phenomenon of cognitive aging - the dedifferentiation of cognitive functions - that is potentially related to dopamine modulation of intraindividual variability. Dedifferentiation refers to an increase in the correlations between various cognitive functions or abilities such as different aspects of intelligence (e.g., Baltes, Cornelius, Spiro, Nesselroade, \& Willis, 1980; Li et al., 2004) or between sensory and cognitive domains of functioning (Baltes \& Lindenberger, 1997; Li, Aggen, Nesselroade, \& Baltes, 2001; Lindenberger \& Baltes, 1994). Evidence from longitudinal studies supports cross-sectional findings on the dedifferentiation of cognitive functions in old age. For instance, de Frias, Lövdén, Lindenberger, \& Nilsson. (2007) found higher correlations among measures of episodic recall, semantic knowledge, and verbal fluency, indicating dedifferentiation in groups aged 65-70 and 75-80 years relative to earlier age cohorts (see also Schaie, Maitland, Willis, \& Intrieri, 1998).

As for potential mechanisms underlying cognitive dedifferentiation, neural network simulations suggest that increased processing noise due to suboptimal gain modulation that simulated deficient DA modulation leads to increased within-network performance variability, resulting in increased coactivation of different processes (Li \& Sikström, 2002) and higher correlations across different cognitive tasks (Li, Lindenberger, et al., 2001). Other than this theoretical link, higher performance variability and process dedifferentiation have mostly been treated as separate phenomena. In the rare case when both questions were addressed in a common study, children and older adults showed greater trial-to-trial variability in a range of RT tasks and, at the same time, also exhibited higher correlations between measures of five primary mental abilities (Li et al., 2004). However, age differences in processing variability and dedifferentiation were only examined in parallel in the study by Li et al.'s (2004) thus, the question whether there is a direct empirical link between intraindividual variability and cognitive dedifferentiation remains open.

Of special interest here, molecular imaging studies have shown that DA neuromodulation affects both episodic memory and working memory. For instance, a single-photon emission computed tomography (SPECT) study reported that striatal D2/D3 receptor density correlated with verbal episodic memory and working memory (Chen et al., 2005). Along the same lines, two positron emission tomography (PET) studies showed that D2 receptor binding in the hippocampus was associated with episodic memory performance as well as with executive functioning (Takahashi et al., 2007, 2008). Thus, at the within-person level, impaired DA modulation may affect episodic memory and working memory and increase processing variability. Increased processing variability, as illustrated in neurocomputational simulations (Li, Lindenberger, et al., 2001; Li \& Sikström, 2002), consequently may lead to increased betweenperson variability in episodic and working memory and result in a higher correlation between these two memory functions.

\subsection{Aims and key hypotheses of the present study}

Integrating the evidence from several lines of research reviewed above, the present study aimed at investigating the effects of performance variability on forgetting and dedifferentiation of memory functions in older adults. Individuals were grouped into lower and higher variability groups on the basis of their performance in a perceptual speed task. Based on earlier results showing that suboptimal DA receptor binding is related to increased RT variability in episodic memory (MacDonald, Cervenka, et al., 2009), we first investigated whether trial-to-trial RT variability is associated with long-term episodic forgetting. We hypothesized that individuals 
with higher variability, reflecting lower DA activity, would exhibit more forgetting after a 1-week retention interval.

Second, we investigated the relation between intraindividual variability and dedifferentiation of memory functions by comparing the factor correlations between measures of episodic memory and working memory as a function of variability. Based both on empirical evidence showing that DA receptor density affects both episodic and working memory (Chen et al., 2005) and the theoretical variability-dedifferentiation link derived from neurocomputational simulations, we hypothesized that the correlation between episodic and working memory would be higher among individuals showing higher variability.

\section{Methods and materials}

\subsection{Participants and sample inclusion criteria}

Five-hundred and seventy-four healthy older adults aged 60-71 years were recruited via newspaper announcements and posters in public transportations. All subjects reported normal or corrected to normal vision and were right-handed, as indexed by the Edinburgh Handedness Index (Oldfield, 1971). All participants scored over 27 on the Mini-Mental Status Examination (MMSE). All participants were not on medications that may affect memory function and did not report a history of head injuries, medical (e.g., heart attack), neurological (e.g., epilepsy), or psychiatric diseases (e.g., depression). All participants had completed at least 8 years of education. Written informed consent was obtained from all subjects, who were paid for their participation. The study was approved by the ethics committees of the Max Planck Institute for Human Development and the Charité University Medicine, Berlin.

\subsection{Measures}

Participants underwent two cognitive testing sessions, 1 week apart. Each session lasted about $3 \mathrm{~h}$ in which participants were tested in groups of about 6 individuals. The cognitive battery measured episodic memory, working memory, executive functioning, perceptual speed as well as other psychometric measures of intelligence (such as Gf and Gc). Responses were given via button boxes and keyboards. The four tasks included in the present study are described in more details below.

\subsubsection{Speed and trial-to-trial variability in the Identical Pictures task}

Trial-to-trial variability was computed as the standard deviation of correct RTs on a perceptual speed measure, the Identical Pictures task. Intraindividual variability in the Identical Pictures task has been related to tasks assessing interindividual differences in frontal lobe functioning, such as conflict monitoring ( $\mathrm{Li}$, Hämmerer, Müller, Hommel, \& Lindenberger, 2009) and verbal fluency (Lövdén et al., 2007). In each trial, participants were presented with five pictures in the lower half of the screen and had to choose which one was identical to a target picture presented in the upper part of the screen. This test included a total of 46 trials and terminated after $80 \mathrm{~s}$. All images were derived from the Kit of Factor-Referenced Cognitive Tests (Ekstrom, French, Harman, \& Derman, 1976; for a detailed description, see Lindenberger, Mayr, \& Kliegl, 1993). Reaction time and number of correct trials were recorded.

\subsubsection{Forgetting between immediate and 1-week delayed recognition memory}

At the beginning of the first session, participants were presented with $48 \mathrm{com}-$ plex, colored images of neutral emotional valence sequentially each for $3 \mathrm{~s}$. All stimuli were derived from the International Affective Picture System (Lang, Bradley, \& Cuthbert, 1997). The images were encoded incidentally; during the study phase, participants were required to determine whether an "indoor" or "outdoor" scene was shown ( 24 indoor and 24 outdoor scenes were presented). The first retrieval test was administered at the end of the first session after a delay of approximately $2.5 \mathrm{~h}$. The second retrieval test was done exactly 1 week later. During retrieval, participants viewed each image for $3 \mathrm{~s}$ and were asked to determine whether each scene was presented ("old") or not presented ("new") during encoding. In each retrieval test, 24 unique old scenes and 24 unique new scenes (lures) were presented. To account for response bias, proportions of hits minus false alarms was used as a measure of recognition (Macmillan \& Creelman, 2005).

\subsubsection{Spatial working memory task (SWM)}

The task used to assess spatial working memory has been described before in Nagel et al. (2008). In this task, dots were presented one at a time in a specific location of a $4 \times 4$ grid. After a sequence of dots was presented, a probe appeared in one of the 16 locations. Participants were required to determine whether a dot had been presented before in this specific location (i.e., location memory condition). If participants gave a yes response, a digit was presented in this location to probe the participants to indicate whether the digit matched the serial position of the dot in the presented series (i.e., sequence memory condition). Working memory load was manipulated by presenting either four or seven dots in a given trial. A total of 96 trials were presented. Here, we focus on the sequence memory condition. We took the mean accuracy for set sizes 4 and 7 to indicate spatial working memory.

\subsubsection{Backward serial recall}

The task used to assess serial order memory was the same as described in Li et al. (2010). Participants were asked to memorize three lists of 12 words each presented via headphones. While the participants listened to the words, they simultaneously saw numbers on the computer screen that represented the serial positions of the words. After list presentation, subjects recalled the items in backward order, beginning with the last item presented (i.e., item 12 to item 1). Given that the recency portion of backward serial recall relies more on short-term memory (Richardson, 2007), backward recall accuracy for the primacy (items 1-4) and middle (items 5-8) portions were used as indicator variables to form the verbal episodic memory factor.

\subsection{Data-based exclusion of participants}

Distributional characteristics of the indicator variables were examined to identify outliers. It is well-known that the distributions of RT and intraindividual variability (iiV) in RT measures are positively skewed; we thus transformed both measures by taking the inverse of the reaction time (1/RT) and variability (1/iiV) measures (Behrens, 1997; Li et al., 2004). Consequently, larger values on the transformed variables were associated with faster reaction times and lower variability. Outlier participants whose $z$-scores exceeded \pm 4 standard deviations on one of the recognition memory measures (immediate recognition, delayed recognition, absolute difference score, i.e., immediate - delayed recognition) or the perceptual speed measures (1/RT, $1 / \mathrm{iiV}$, number of correct responses) were excluded from the analysis ( $<1 \%$ in total). Furthermore, participants with negative hits minus false alarms scores in the immediate or delayed recognition tasks were excluded (3.7\%), as this usually indicates that the task was performed inappropriately. Furthermore, participants who scored higher in delayed than in immediate recognition (4\%) were also excluded because these participants were characterized by significantly more nonresponses in the immediate recognition memory test, suggesting either technical errors during testing (e.g., key malfunctioning) or inappropriate response behavior (e.g., pressing wrong response keys). The final sample consisted of 524 older adults (age range $=60.1-71.2$ years, mean age $=65.1, S D=2.8 ; 298$ women and 226 men).

\subsection{Defining extreme groups}

We applied an extreme-group approach to sort participants into upper-third and lower-third groups based on their performance.

The extreme-group approach increases the statistical power for detecting small effects (Feldt, 1961; Preacher, Rucker, MacCallum, \& Nicewander, 2005). This property is particularly relevant for several reasons in the present study. First, as reviewed above, the literature on forgetting suggests that interindividual differences in forgetting are difficult to detect. Second, we studied a relatively homogeneous sample of healthy older adults, which limits the range of interindividual variations in forgetting and reduces the likelihood of observing moderate or large effect sizes. Third, the measure of forgetting is a difference score. This may potentially set a limit on the observable relation between variables due to the often discussed low reliability of difference score measures (e.g., Bonate, 2000).

To investigate our key hypotheses, participants were first grouped based on the transformed variability measure (i.e., 1/iiV). Given that the transformed measure reflects the inverse of RT variability, individuals from the upper tercile of the distribution were sorted into the low-variability group, whereas individuals from the lower tercile were sorted into the high-variability group. For the purpose of control analyses, two other types of grouping were also performed. A group of low-speed and a group of high-speed individuals were identified based on the transformed speed measure. Finally, two memory decay groups were selected based on the absolute difference (Rogosa, Brandt, \& Zimowski, 1982) of the proportion of hits minus false alarms in the episodic recognition task (immediate recognition delayed recognition), with higher values being associated with more forgetting. The non-overlap in grouping was $43 \%$ comparing the variability and speed groups and over $60 \%$ comparing the decay groups with either the variability or speed groups, ensuring partial independence of the analyses targeting the different groupings. All analyses focused on the extreme groups. A detailed sample description of the different groups is presented in Table 1. Given that memory performance may be influenced by vascular health (e.g., Elias et al., 1997; Raz et al., 2008), extreme groups were also characterized with respect to a range of relevant indicators, including diabetes, diagnoses of cardiovascular disease, and arterial hypertension. Importantly, there were no differences between the key independent factors (i.e., variability and speed groups) with respect to the markers of vascular health or on a derived measure of hypertension grade (see Table 1 for details). This latter measure was computed according to the guidelines published by the World Health Organization (WHO) and the International Society of Hypertension (ISH; WHO, ISH Writing Group, 2003). As for the dependent factor (i.e., memory decay groups), there were small effects of the percentage of diabetics and hypertensives being higher in the low-decay group, relative to the high-decay group. Note, however, the direction of the effects countered the expected negative influence of hypertension on memory and thus could not bias the results in favoring of our predictions. 
Table 1

Demographic variables split by speed, variability, and decay groups.

\begin{tabular}{|c|c|c|c|c|c|c|}
\hline & \multicolumn{2}{|c|}{ Variability grouping } & \multicolumn{2}{|c|}{ Speed grouping } & \multicolumn{2}{|c|}{ Decay grouping } \\
\hline & $\begin{array}{l}\text { Low } \\
n=174\end{array}$ & $\begin{array}{l}\text { High } \\
n=175\end{array}$ & $\begin{array}{l}\text { High } \\
n=175\end{array}$ & $\begin{array}{l}\text { Low } \\
n=175\end{array}$ & $\begin{array}{l}\text { Low } \\
n=175\end{array}$ & $\begin{array}{l}\text { High } \\
n=175\end{array}$ \\
\hline \multicolumn{7}{|l|}{ Demographics } \\
\hline Age $(M \pm S D)$ & $64.7(2.8)$ & $65.4(2.8)$ & $64.4(2.8)$ & $65.6(2.8)$ & $64.7(2.8)$ & $65.4(2.7)^{\mathrm{a}}$ \\
\hline Women/men & $93 / 81$ & $115 / 60$ & $93 / 82$ & $109 / 66$ & $93 / 82$ & $119 / 56^{\mathrm{b}}$ \\
\hline Year of education $(M \pm S D)$ & $10.9(1.7)$ & $10.9(1.9)$ & $11.0(1.6)$ & $10.7(1.8)$ & $10.8(1.6)$ & $11.0(1.8)^{\mathrm{c}}$ \\
\hline State of health $(M \pm S D)$ & $3.9(0.6)$ & $3.9(0.6)$ & $3.9(0.6)$ & $3.8(0.6)$ & $3.9(0.6)$ & $3.9(0.7)^{c}$ \\
\hline $\operatorname{MMSE}(M \pm S D)$ & $29.4(0.7)$ & $29.4(0.7)$ & $29.4(0.7)$ & $29.4(0.7)$ & $29.4(0.7)$ & $29.4(0.7)^{\mathrm{c}}$ \\
\hline \multicolumn{7}{|l|}{ Indicators of vascular health } \\
\hline Diabetes & $6.9 \%$ & $4 \%$ & $6.3 \%$ & $5.2 \%$ & $8.6 \%$ & $3.4 \% \mathrm{~d}$ \\
\hline Cardiovascular disease & $34.7 \%$ & $38.9 \%$ & $32.6 \%$ & $36.2 \%$ & $32.8 \%$ & $33.7 \% \mathrm{c}$ \\
\hline Hypertension medication & $31.8 \%$ & $36 \%$ & $29.1 \%$ & $33.9 \%$ & $28.7 \%$ & $30.3 \%^{\mathrm{c}}$ \\
\hline Hypertension grade $(M \pm S D)$ & $1.54(.93)$ & $1.43(1.0)$ & $1.61(.96)$ & $1.52(1.0)$ & $1.63(.92)$ & $1.44(1.0)^{\mathrm{c}}$ \\
\hline Percentage of hypertensives & $90.2 \%$ & $84.6 \%$ & $90.9 \%$ & $84.6 \%$ & $92.6 \%$ & $84 \%{ }^{\mathrm{e}}$ \\
\hline
\end{tabular}

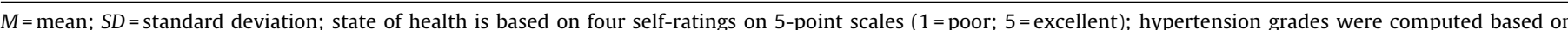

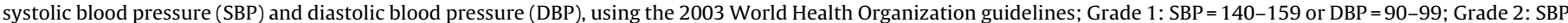

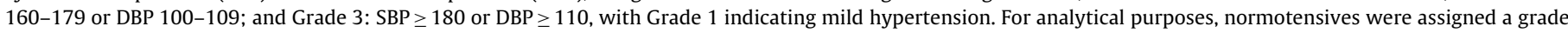

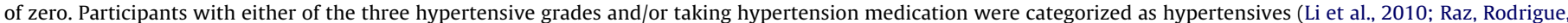
Kennedy, \& Land, 2009).

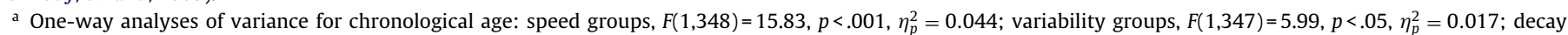
groups, $F(1,348)=5.10, p<.05, \eta_{p}^{2}=0.014$.

b Variability groups, $\chi_{\text {sex }}^{2}(1, n=349)=5.45, p<.05$; decay groups, $\chi_{\text {sex }}^{2}(1, n=350)=8.09, p<.01$.

c n.s.

d Variability and Speed groups, $\chi_{\text {diabetes }}^{2}(1)=n . s$; decay groups, $\chi_{\text {diabetes }}^{2}(1, n=349)=4.16, p<.05$.

e Variability and Speed groups, $\chi_{\text {hypertensives }}^{2}(1)=n . s$.; decay groups, $\chi_{\text {hypertensives }}^{2}(1, n=349)=6.22, p<.05$.

\section{Results}

\subsection{Summary of analyses and covariates}

Behavioral data, testing our first hypothesis that variability is related to forgetting, and demographic data were analyzed using SPSS for Windows 15.0 (SPSS, Chicago, IL). In addition, we conducted two sets of comparison analyses (i.e., the effects of speed grouping on forgetting and the effect of memory decay grouping on variability and speed) to ascertain that the predicted effect of processing variability on forgetting is unique. For all analyses, partial eta squared $\left(\eta_{p}^{2}\right)$ was used to indicate effect sizes and the alpha level was set to $p=.05$. Four covariates were included in the analysis of covariance (ANCOVA) reported below. Chronological age was entered as a covariate to control for differences in age among extreme groups (see Table 1). Sex was used as a covariate for two reasons: (i) the female advantage in episodic memory is a common finding (e.g., Herlitz, Nilsson, \& Bäckman, 1997), and (ii) unequal distributions of sex in the extreme groups, with women being overrepresented in the high-variability and high-decay groups (see Table 1). Third, because larger variability is usually associated with higher mean response times (e.g., Shammi, Bosman, \& Stuss, 1998), mean RT in the Identical Pictures task was used as a covariate in order to ensure that group differences in variability were not due to group differences in speed (i.e., 1/RT). Conversely, intraindividual variability was covaried out in analyses involving the speed groups. Finally, the number of correctly completed items in the Identical Pictures task was chosen as a forth covariate in all analyses with the variability groups because previous research has shown that accuracy on measures of perceptual speed predicts changes in episodic memory (Hertzog, Dixon, Hultsch, \& MacDonald, 2003).

To test our second hypothesis that individuals with greater processing fluctuations also show more dedifferentiated memory functions, we examined the latent factor correlations between measures of working memory and episodic memory in the highand low-variability groups using structural equation modeling (SEM; Kline, 2005). First, measurement invariance between highand low-variability groups was evaluated by applying multiple group confirmatory factor analyses using AMOS 7.0 (Arbuckle, 2006a, b; Byrne, 2004).

A series of progressively more stringent models was evaluated, constraining different aspects of the measurement models (factor loadings, residuals, factor covariances) to be equal across variability groups. Given that the more constrained models were nested within the initial model, the difference in $\chi^{2}$ fit statistics $\left(\Delta \chi^{2}\right)$ was used to determine whether the more parsimonious model could be accepted. The alpha-level for statistical decisions regarding difference in $\chi^{2}$ fit statistics was set at the .05 level. For reasons given above, sex and chronological age were included as covariates in all SEM analyses as well. The following fit indices were used to examine model fit for the confirmatory factor analyses: the normed chi-square $\left(\chi^{2} / d f\right)$, Akaike's information criterion (AIC), the root mean square error of approximation (RMSEA), and the comparative fit index (CFI; see Kline, 2005, for interpretation of these indices). Behavioral data used in latent factor analyses were transformed into z scores across the variability groups. The assumption of multivariate normality was tenable, as Mardia's coefficient of multivariate kurtosis provided by AMOS was not statistically significant $(p>.05)$.

\subsection{The relation between intraindividual variability and forgetting}

Central to our hypothesis about the relation between variability and forgetting, we conducted a two-way mixed design repeated measures ANCOVA with variability group (low, high) as betweensubjects factor and session (immediate, delayed recognition) as within-subjects factor. This analysis yielded a significant effect for the critical interaction between variability group and session, $F(1,343)=4.0, p<.05, \eta_{p}^{2}=0.011$. As can be seen in Fig. $1 \mathrm{~A}$, although the two variability groups performed equally well in immediate recognition memory, individuals in the high-variability group performed worse in the delayed recognition condition, indicating more had been forgotten, than individuals in the low-variability group. There were no overall main effects of variability group $(F<1)$ and $\operatorname{session}(F=2.94$, n.s. $)$. 
$\mathbf{A}$

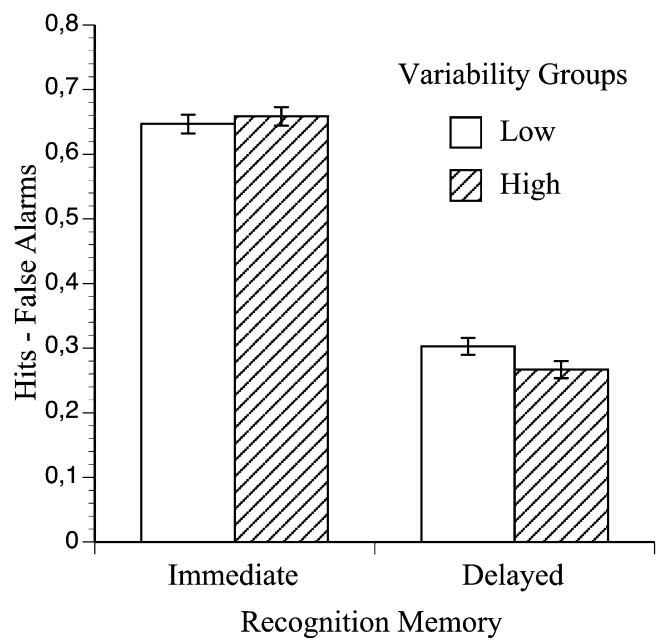

B

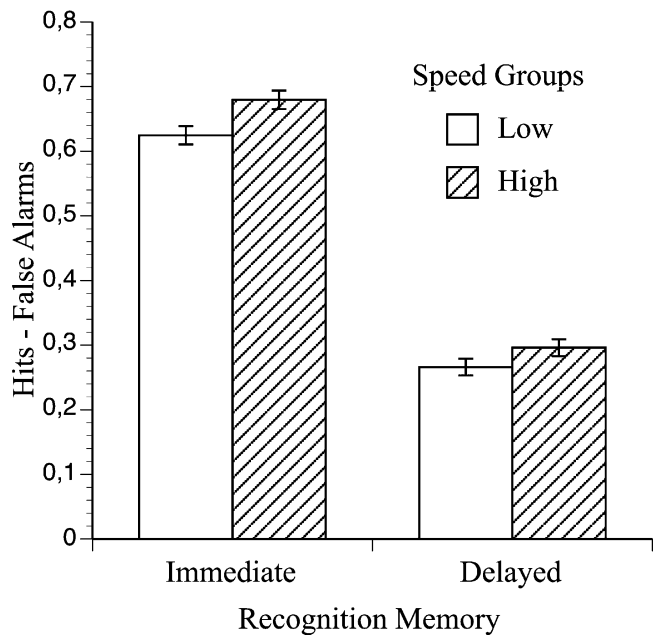

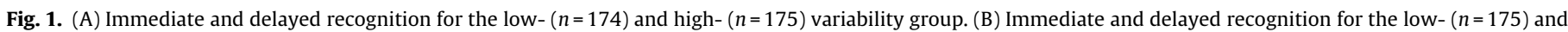
high- $(n=175)$ speed group. Error bars represent one standard error around the mean.

As for the comparison analyses, a speed group (low, high) $\times$ session (immediate, delayed recognition) mixed ANCOVA revealed only a significant main effect of speed group, $F(1,345)=5.3$, $p<.05, \eta_{p}^{2}=0.015$. As can be seen in Fig. $1 \mathrm{~B}$, individuals in the low-speed group showed lower performance overall. However, speed was not associated with more forgetting, because the speed group $\times$ forgetting interaction was not reliable $(p>.10)$. In two univariate ANCOVAs, we also tested whether the decay groups (low, high) would differ with respect to intraindividual variability and mean reaction time. However, for these control analyses, we did not find any significant main effects of group on intraindividual variability, $F(1,344)=2.3$, n.s., nor on mean reaction time, $F(1,345)=1.8$, n.s.

\subsection{The relation between intraindividual variability and memory dedifferentiation}

In the first step, a factor model was specified with two latent variables, each with two indicators. Fig. 2 displays a graphical representation of the factor model. The reference model (Model 1) was identified by fixing the variances of the latent variables to 1 and constraining the factor loadings for each factor to be equal in each group, testing for configural invariance. The fit of this reference model (Model 1) was acceptable, $\chi^{2}(16)=35.48, p<.01$, $\mathrm{AIC}=87.5$, RMSEA $=.059,90 \% \mathrm{CI}_{\text {RMSEA }}[.03,09], \mathrm{CFI}=.93$. The second, more constrained, model (Model 2) tested the hypothesis of identical magnitude of factor loadings across groups, i.e., metric (or weak) factorial invariance; cf. Meredith (1964). Model 2 also exhibited an acceptable fit, $\chi^{2}(18)=36.14, p<.01$, AIC $=84.1$, RMSEA $=.054,90 \% \mathrm{CI}_{\text {RMSEA }}[.03,08], \mathrm{CFI}=.93$, and the restriction did not result in significantly worse fit compared to Model $1, \Delta \chi^{2}=.66$, $\Delta d f=2, p>.05$. Next, in addition to factor loadings, the residual variances were constrained to be the same across groups (Model 3 ). The fit of Model 3 remained acceptable, $\chi^{2}(24)=48.98, p<.01$, $\mathrm{AIC}=85.0, \mathrm{RMSEA}=.055,90 \% \mathrm{CI}_{\text {RMSEA }}[.03,08], \mathrm{CFI}=.91$. However, the chi-square difference test was significant, $\Delta \chi^{2}=12.84, \Delta d f=6$, $p<.05$, indicating that the residual variances could not be equated across the two variability groups. The level of invariance achieved (i.e., metric invariance) was maintained for the analyses of factor intercorrelations. We then specified a model in which the interfactor correlations for the two groups were constrained to be equal, $\chi^{2}(19)=43.20, p<.01, \mathrm{AIC}=89.2, \mathrm{RMSEA}=.061,90 \% \mathrm{CI}_{\mathrm{RMSEA}}[.04$, 09 ], $\mathrm{CFI}=.91$ (Model 4). A direct comparison to Model 2 revealed that this equality constraint was associated with a reliable decrement in model fit, $\Delta \chi^{2}=7.06, \Delta d f=1, p<.05$, indicating that the factor intercorrelations differed significantly between the two variability groups. Thus, Model 2 of metric invariance but different factor correlations exhibited the best fit. In this model, the correlation between the working memory and episodic memory factors was higher in the high-variability group $(r=.63, p<.001)$ compared to the low-variability group $(r=.25, p<.05)$. Fig. 2 displays the stan-

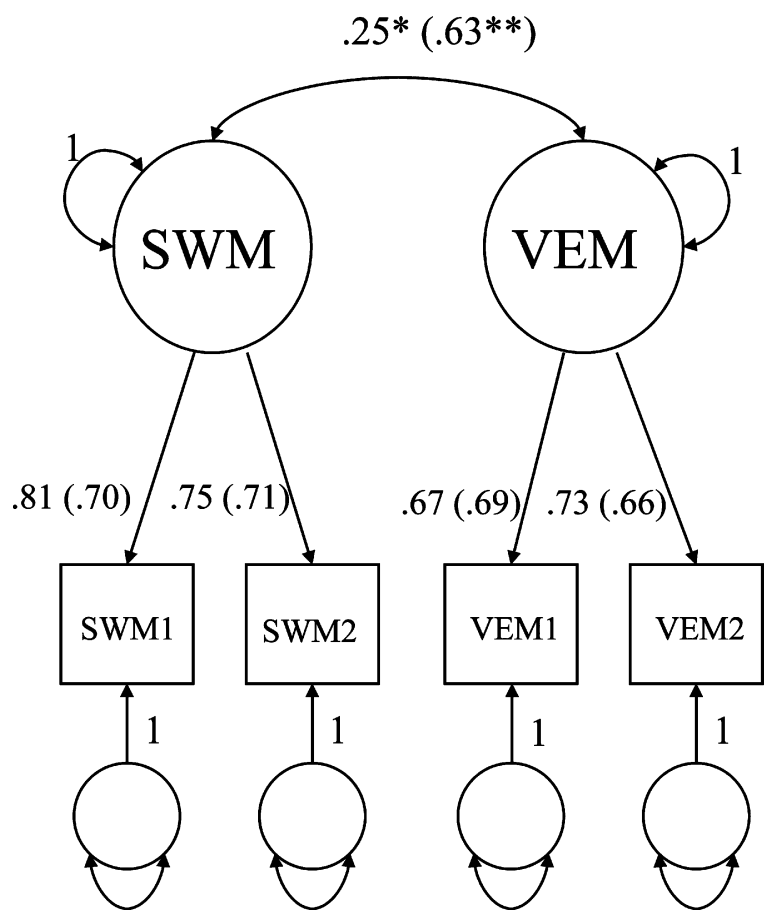

Fig. 2. Factor model used in multiple group analyses on the relation between variability and dedifferentiation of memory processes (shown here is Model 2, the metric invariant model, see text and Table 2). The standardized factor loadings and interfactor correlation for the high-variability group are shown in parentheses. Sex and chronological age are not shown in the figure, but were included as covariates on the latent constructs in all analyses. SWM, spatial working memory factor; VEM, verbal episodic memory factor; SWM1, SWM accuracy for sequence memory set size 4 condition; SWM2, SWM accuracy for sequence memory set size 7 condition; VEM1, backward recall for primacy portion (items 1-4); VEM2, backward recall for middle portion (items $5-8$ ). ${ }^{*} p<.05$ and ${ }^{* *} p<.001$. 
Table 2

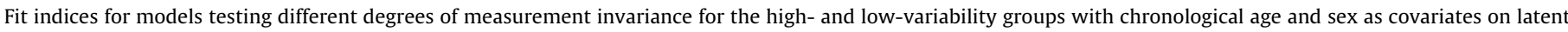
constructs.

\begin{tabular}{|c|c|c|c|c|c|c|c|c|c|c|}
\hline Model & $\chi^{2}$ & $d f$ & $\chi^{2} / d f$ & AIC & RMSEA & $90 \%$ CI for RMSEA & $\mathrm{CFI}$ & $\Delta \chi^{2}$ & $\Delta d f$ & $\Delta p$ \\
\hline \multicolumn{11}{|l|}{ Model 1: } \\
\hline Configural invariance & 35.48 & 16 & 2.22 & 87.5 & .059 & {$[.03, .09]$} & .93 & - & - & - \\
\hline \multicolumn{11}{|l|}{ Model 2: } \\
\hline Metric invariance & 36.14 & 18 & 2.01 & 84.1 & .054 & {$[.03, .08]$} & .93 & .66 & 2 & .719 \\
\hline \multicolumn{11}{|l|}{ Model 3: } \\
\hline Metric invariance and equal residual variances & 48.98 & 24 & 2.04 & 85.0 & .055 & {$[.03, .08]$} & .91 & 12.84 & 6 & .046 \\
\hline \multicolumn{11}{|l|}{ Model 4: } \\
\hline Metric invariance and equal factor covariance & 43.20 & 19 & 2.27 & 89.2 & .061 & {$[.04, .09]$} & .91 & 7.06 & 1 & .008 \\
\hline
\end{tabular}

AIC, Akaike's information criterion; RMSEA, root mean square error of approximation; CI, confidence interval; CFI, comparative fit index.

dardized factor loadings and the interfactor correlations of Model 2. Fit statistics are summarized in Table 2.

Given that measures of perceptual speed are often regarded as sensitive indicators of cognitive aging (Salthouse, 1996), we also conducted comparison analyses with the speed grouping. In this case, we were able to establish configural and metric invariance. In addition, equating the residual variances and the factor covariances across groups did not result in significantly worse model fit. Importantly, constraining the factor correlations in this case, however, did not lead to a reduction in fit, indicating that the correlations between the memory factors can be constrained to be equal $(r=.39, p<.001$ ) for both speed groups (due to space limitation, other details about the control analysis, such as raw correlations, model fit statistics, factor loadings, and interfactor correlations for the model with the best fit, are reported in the Appendix).

\section{Discussion}

In light of recent empirical findings of (i) lower DA D2 receptor density being associated with greater performance variability in episodic memory (MacDonald, Cervenka, et al., 2009), and (ii) the involvement of DA in episodic memory consolidation (Bethus et al., 2010; O'Carroll et al., 2006), we hypothesized that individuals with higher intraindividual variability would exhibit more forgetting, presumably reflecting suboptimal dopaminergic neuromodulation. Furthermore, we examined whether higher processing variability is associated with the dedifferentiation of memory functions. Based on (i) neurocomputational modeling work linking suboptimal DA modulation to increases in performance variability and subsequent dedifferentiation (Li, Lindenberger, et al., 2001) and (ii) findings documenting that working memory and episodic memory both are related to DA functioning (Bäckman et al., 2000; Chen et al., 2005; Erixon-Lindroth et al., 2005), we hypothesized that higher performance variability would result in higher correlations between these memory functions.

As expected, intraindividual variability was associated with amount of forgetting, independent of mean performance levels, with the high-variability group showing more forgetting than the low-variability group. The relation between processing variability and forgetting was unique, as the comparison analyses using speed and forgetting as grouping criteria yielded very different patterns of results. These findings are in line with previous studies suggesting that, although intraindividual variability and speed share substantial variance, RT variability as a measure provides information beyond mean RT (Li et al., 2004, 2009; Ram, Rabbitt, Stollery, \& Nesselroade, 2005; Schmiedek, Lövdén, \& Lindenberger, 2009). Grouping participants on a memory difference score (i.e., immediate-delayed recognition memory) did not yield statistically reliable between-group differences either with respect to performance variability or processing speed; grouping based on mean reaction time revealed a main effect of group on overall episodic memory performance, but did not have an effect on forgetting.
In this study, we found that individual differences in processing variability predict episodic memory forgetting in old age. This finding is noteworthy given the notorious difficulties in isolating individual differences or experimental manipulations that uniquely predict forgetting (see MacDonald, Stigsdotter-Neely, et al., 2006, for review). At the same time, our results are in line with two sets of evidence underscoring DA's effect on processing noise and memory consolidation. Both earlier computational theories (Li, Lindenberger, et al., 2001) as well as recent empirical results from receptor imaging studies (MacDonald, Cervenka, et al., 2009) suggest that individual differences in DA signaling affect performance variability. Furthermore, several lines of findings show that DA is involved in long-term episodic memory. Animal research shows that stimulation of dopamine receptors in the hippocampus enhances memory performance by facilitating long-term potentiation (Frey, Huang, \& Kandel, 1993; Huang \& Kandel, 1995), a cellular mechanism critical to long-term memory (Cooke \& Bliss, 2006). Based on these findings, it has been suggested that a functional loop involving the dopaminergic midbrain and the hippocampus controls long-term memory formation (for review, see Lisman \& Grace, 2005). In healthy adults, this notion is supported by a PET study that found a strong relationship between striatal DA D2 receptor binding and a measure of episodic memory (Cervenka et al., 2008). Further, imaging studies have documented that coactivation of dopaminergic midbrain regions (substantia nigra and ventral tegmental area) and the hippocampus during encoding is associated with enhanced long-term memory formation of rewardrelated stimuli (Adcock, Thangavel, Whitfield-Gabrieli, Knutson, \& Gabrieli, 2006; Wittmann et al., 2005). Also in line with our findings, animal data show that infusion of DA antagonist in the hippocampus impairs long-term memory, but leaves short-term memory intact (Bethus et al., 2010; O'Carroll et al., 2006). Another study highlights the importance of DA availability after $12 \mathrm{~h}$ for memory consolidation (Rossato, Bevilaqua, Izquierdo, Medina, \& Cammarota, 2009). These authors observed a rapid decay of already existing fearful memories after the injection of a D1 receptor antagonist into the hippocampus of rats $12 \mathrm{~h}$ after a fearful experience, whereas the injection of a D1 agonist resulted in a persistent fear memory.

Our finding of individual differences in perceptual speed being related to overall memory performance, but not to forgetting, suggests that individual differences in speed, though also related to DA modulation (e.g., Bäckman et al., 2000; Volkow et al., 1998), may primarily arise from other factors contributing to structural and metabolic integrity in the brain (e.g., Bucur et al., 2008; Charlton, Barrick, Markus, \& Morris, 2010; Kochunov et al., 2010; Madden, Bennett, \& Song, 2009). For instance, measures of cognitive and motor speed have been linked to neuroimaging indicators of myelin breakdown in older adults (Bartzokis et al., 2007, 2010). This relationship between myelin and speed is further evidenced in patients with demyelinating diseases, such as multiple sclerosis, who show reduced information processing speed compared to healthy con- 
trols (e.g., Kail, 1998). Myelin degeneration has also been suggested to, at least partly, underlie aging-related changes in white matter integrity (Davis et al., 2009). Of special interest, our finding of speed grouping being associated with overall memory performance is in agreement with recent data showing that processing speed had virtually identical effects in mediating the associations between white matter integrity and immediate and delayed memory (Charlton et al., 2010). Thus, the observed differential effects of speed and variability on mean episodic memory performance and forgetting, respectively, might reflect the relative contributions of different brain mechanisms underlying speed and variability measures.

Regarding the relation between performance variability and dedifferentiated memory functions, we found that the correlation between episodic memory and spatial working memory was considerably higher in the high-variability than in the low-variability group $(r=.63$ for higher variability vs. $r=.25$ for lower variability). This finding was unique to the variability grouping: results from the comparison analyses using speed as the grouping factor did not affect the relation between these two memory functions ( $r=.39$ for both the high- and low-speed groups). Thus far, other than the theoretical link explicated in earlier computational studies (Li \& Lindenberger, 1999; Li \& Sikström, 2002), the association between performance variability and ability dedifferentiation has only been investigated indirectly in an age-heterogeneous lifespan sample (Li et al., 2004). Critically, the present results extend this finding to a relatively narrow age sample of older adults (cf. Hofer \& Sliwinski, 2001) and more directly examined the effect of within-person variability on process dedifferentiation through the extreme-group design.

We focused on two cognitive domains (i.e., working memory and episodic memory) known to be sensitive to deficits in dopaminergic neuromodulation (e.g., Aalto, Brück, Laine, Någren, \& Rinne, 2005; Bäckman et al., 2000; Erixon-Lindroth et al., 2005; McNab et al., 2009; Nyberg et al., 2009; Sawaguchi \& GoldmanRakic, 1991; Schott et al., 2006). These two memory functions share similar underlying neural networks, involving the frontostriatal circuitry (e.g., Chen et al., 2005; Fletcher, Shallice, \& Dolan, 1998; Fletcher, Shallice, Frith, Frackowiak, \& Dolan, 1998; Smith \& Jonides, 1999) and the medial temporal lobe (e.g., Axmacher Elger, \& Fell, 2009; Ezzyat \& Olson, 2008; Park et al., 2003; Piekema et al., 2007; Squire, Stark, \& Clark, 2004). Striatal D2 receptor density has been associated with measures of episodic memory and working memory (Bäckman et al., 2000; Chen et al., 2005; ErixonLindroth et al., 2005). Similarly, D2 binding in the hippocampus was associated not only with episodic memory, but also with executive functioning (Takahashi et al., 2007, 2008), the latter being closely related to spatial-working memory (Busch et al., 2005; Fisk \& Sharp, 2003; Rudkin, Pearson, \& Logie, 2007). Juxtaposing this evidence and the theoretical link between variability and dedifferentiation (Li, Lindenberger, et al., 2001), our data suggest that suboptimal DA modulation may lead to increases in both withinperson and between-person variability in episodic and working memory, resulting in a higher factor correlation of these two memory functions.

Some limitations of the present investigation should be acknowledged. First, we used an extreme-group design for data analysis. The main advantage of this design is its greater statistical power for hypothesis testing. However, it should also be underscored that the increased power may come with a cost in overestimating population effect sizes (Preacher et al., 2005).Second, dopamine neuromodulation was not directly measured. As noted above, increases in intraindividual reaction time variability may also be due to structural and functional brain changes (MacDonald, Li, et al., 2009; MacDonald, Nyberg, et al., 2006). Specifically, increased trial-to-trial variability is associated with smaller white matter volume (Walhovd \& Fjell, 2007) and white matter hyperintensities in the frontal lobes in healthy older adults (Bunce et al., 2007). Intraindividual variability has also been linked to graymatter integrity, particularly in the frontal cortex (Murtha et al., 2002; Stuss et al., 2003). In addition, increased functional brain activations have been related to lower intraindividual variability and better word recognition in older adults (MacDonald, Nyberg, Sandblom, Fischer, \& Bäckman, 2008) as well as higher intraindividual variability and lower executive functioning in middle-age adults (Bellgrove, Hester, \& Garavan, 2004). Other factors such as higher stress (Sliwinski, Smyth, Hofer, \& Stawski, 2006) and sleep deprivation (Habeck et al., 2004) may also result in increased reaction time variability. Thus, in view of other operating factors, it is important to link deficient dopaminergic neuromodulation more directly to greater performance variability, forgetting, and dedifferentiation in future studies. Here, additional information based on receptor imaging and genetics would be especially useful.

Third, related to this point, the question remains whether intraindividual RT variability is a qualitatively distinct marker of dopamine status. This issue is of theoretical significance because other indices, such as fluid intelligence, have also been associated with intraindividual variability (Li et al., 2004, 2009; Rabbitt, Osman, Moore, \& Stollery, 2001; Ram et al., 2005) and dopamine neuromodulation (e.g., Bäckman et al., 2000; Bolton et al., 2010; Volkow et al., 1998). Direct comparisons of the associations of variability measures and other indices of cognitive performance to dopamine neuromodulation are needed to shed light on this issue.The present study makes two novel contributions to the existing literature on performance variability. First, interindividual differences in trial-to-trial variability are related to interindividual changes in levels of performance at the intermediate timescale, i.e., episodic memory forgetting over 1 week. Second, grouping individuals into high- and low-variability groups provided a more direct way to examine the relation between processing variability and the dedifferentiation of memory functions. Together, our findings support the idea that processing fluctuation is an important marker of cognitive and presumably of neural integrity. Genetic, neuromodulatory, and other brain mechanisms contributing to individual differences in processing fluctuation may not only affect specific cognitive processes, but also the functional organization of a cognitive system as a whole (cf. Li et al., 2004; Li, Brehmer, Shing, Werkle-Bergner, \& Lindenberger, 2006).

\section{Conflict of interest statement}

The authors declare that there is no conflict of interest.

\section{Acknowledgements}

This research was supported by the Max Planck Society, including grants from the innovation fund of the Max Planck Society (M.FE.Abild0005). It was also supported by a grant from the German Federal Ministry of Education and Research to the Berlin NeuroImaging Center (01G00501). L.B. was supported by the Swedish Research Council (521-2007-2892), Swedish Brain Power, and by an Alexander von Humboldt Research Award. G.P. is a fellow of the International Max Planck Research School, The Life Course: Evolutionary and Ontogenetic Dynamics (LIFE). The authors thank Kirsten Becker, Ute Martin, Ludmila Müller, and the other research assistants for their help.

\section{Appendix A. Supplementary data}

Supplementary data associated with this article can be found, in the online version, at doi:10.1016/j.neuropsychologia.2011.03.013. 


\section{References}

Aalto, S., Brück, A., Laine, M., Någren, K., \& Rinne, J. (2005). Frontal and temporal dopamine release during working memory and attention tasks in healthy humans: A positron emission tomography study using the high affinity dopamine D2 receptor ligand [11C] FLB 457. Journal of Neuroscience, 25, 2471-2477. doi:10.1523/JNEUROSCI.2097-04.2005

Adcock, R. A., Thangavel, A., Whitfield-Gabrieli, S., Knutson, B., \& Gabrieli, J. D. (2006). Reward-motivated learning: Mesolimbic activation precedes memory formation. Neuron, 50, 507-517. doi:10.1016/j.neuron.2006.03036

Arbuckle, J. L. (2006a). Amos (Version 7.0) [Computer Program]. Chicago: SPSS.

Arbuckle, J. L. (2006b). Amos 7.0 User's Guide. Chicago: SPSS

Axmacher, N., Elger, C. E., \& Fell, J. (2009). Working memory-related hippocampal deactivation interferes with long-term memory formation. Journal of Neuroscience, 29, 1052-1960. doi:10.1523/JNEUROSCI.5277-08.2009

Bäckman, L., Ginovart, N., Dixon, R. A., Wahlin, T. B., Wahlin, A., Halldin, C., et al. (2000). Age-related cognitive deficits mediated by changes in the striatal dopamine system. The American Journal of Psychiatry, 157, 635-637. doi:10.1176/appi.ajp.157.4.635

Baltes, P. B., Cornelius, S. W., Spiro, A., Nesselroade, J. R., \& Willis, S. L. (1980). Integration versus differentiation of fluid/crystallized intelligence in old age. Developmental Psychology, 16, 625-635. doi:10.1037/0012-1649. 16.6.625

Baltes, P. B., \& Lindenberger, U. (1997). Emergence of a powerful connection between sensory and cognitive functions across the adult life span: A new window to the study of cognitive aging? Psychology and Aging, 12, 12-21. doi:10.1037/0882-7974.12.1.12

Bartzokis, G., Lu, P. H., Geschwind, D., Tingus, K., Huang, D., Mendez, M. F., et al. (2007). Apolipoprotein E affects both myelin breakdown and cognition: Implications for age-related trajectories of decline into dementia. Biological Psychiatry, 62, 1380-1387. doi:10.1016/j.biopsych.2007.03.024

Bartzokis, G, Lu, P. H., Tingus, K., Mendez, M. F., Richard, A., Peters, D. G., et al. (2010). Lifespan trajectory of myelin integrity and maximum motor speed. Neurobiology of Aging, 31, 1554-1562. doi:10.1016/j.neurobiolaging.2008.08.015

Behrens, J. T. (1997). Principles of exploratory data analysis. Psychological Methods, 2, 131-160.

Bellgrove, M. A., Hawi, Z., Kirley, A., Gill, M., \& Robertson, I. H. (2005). Dissecting the attention deficit hyperactivity disorder (ADHD) phenotype: Sustained attention, response variability and spatial attentional asymmetries in relation to dopamine transporter (DAT1) genotype. Neuropsychologia, 43, 1847-1857. doi:10.1016/j.neuropsychologia.2005.03.011

Bellgrove, M. A., Hester, R., \& Garavan, H. (2004). The functional neuroanatomical correlates of response variability: Evidence from a response inhibition task. Neuropsychologia, 42, 1910-1916. doi:10.1016/j.neuropsychologia. 2004.05.007

Bethus, I., Tse, D., \& Morris, R. G. M. (2010). Dopamine and memory: Modulation of the persistence of memory for the novel hippocampal NMDA receptor-dependent paired associates. Journal of Neuroscience, 30, 1610-1618. doi:10.1523/JNEUROSCI 2721-09.2010

Bolton, J. L., Marioni, R., Deary, I. J., Harris, S. E., Stewart, M., Murray, G., et al. (2010). Association between polymorphisms in the dopamine receptor D2 and catechol-O-methyltransferase genes and cognitive function. Behavior Genetics, 40, 630-638. doi:10.1007/s10519-010-9372-y

Bonate, P. (2000). Analysis of pretest-postest designs. Boca Raton, FL: Chapman \& Hall/CRC.

Bucur, B., Madden, D. J., Spaniol, J., Provenzale, J. M., Cabeza, R., White, L. E., et al. (2008). Age-related slowing of memory retrieval: Contributions of perceptual speed and cerebral white matter integrity. Neurobiology of Aging, 29, 1070-1079. doi:10.1016/j.neurobiolaging.2007.02.008

Bunce, D., Anstey, K. J., Christensen, H., Dear, K., Wen, W., \& Sachdev, P. (2007). White matter hyperintensities and within-person variability in community-dwelling adults aged 60-64 years. Neuropsychologia, 45, 2009-2015. doi:10.1016/j.neuropsychologia.2007.02.006

Busch, R. M., Booth, J. E., McBride, A., Vanderploeg, R. D., Curtiss, G., \& Duchnick, J. J. (2005). Role of executive functioning in verbal and visual memory. Neuropsychology, 19, 171-180. doi:10.1037/0894-4105.19.2.171

Byrne, B. (2004). Testing for multigroup invariance using AMOS Graphics: A road less traveled. Structural Equation Modeling: A Multidisciplinary Journal, 11, 272-300, doi:10.1207/s15328007sem1102_8.

Cervenka, S., Bäckman, L., Cselényi, Z., Halldin, C., \& Farde, L. (2008). Associations between dopamine D2-receptor binding and cognitive performance indicate functional compartmentalization of the human striatum. Neuroimage, 40,1287-1295, doi:10.1016/j.neuroimage.2007.12.063.

Charlton, R. A., Barrick, T. R., Markus, H. S., \& Morris, R. G. (2010). The relationship between episodic long-term memory and white matter integrity in normal aging. Neuropsychologia, 48, 114-122, doi:10.1016/ j.neuropsychologia.2009.08.018.

Chen, P. S., Yang, Y. K., Lee, Y. -S., Yeh, T. L., Lee, I. H., Chiu, H. L., et al. (2005). Correlation between different memory systems and striatal dopamine D2/D3 receptor density: A single photon emission computed tomography study. Psychological Medicine, 35, 197-204. doi:10.1017/S0033291704003101

Christensen, H., Kopelman, M. D., Stanhope, N., Lorentz, L., \& Owen, P. (1998). Rates of forgetting in Alzheimer dementia. Neuropsychologia, 36, 547-557, doi:10.1016/S0028-3932(97)00116-4.

Cooke, S. F., \& Bliss, T. V. P. (2006). Plasticity in the human central nervous system. Brain, 129, 1659-1673, doi:10.1093/brain/awl082.
Craddock, N., Owen, M. J., \& O’Donovan, M. C. (2006). The catechol-O-methyl transferase (COMT) gene as a candidate for psychiatric phenotypes: Evidence and lessons. Molecular Psychiatry, 11, 446-458, doi:10.1038/sj.mp.4001808.

Davis, S. W., Dennis, N. A., Buchler, N. G., White, L. E., Madden, D. J., \& Cabeza, R. (2009). Assessing the effects of age on long white matter tracts using diffusion tensor tractography. Neuroimage, 46, 530-541 doi:10.1016/j.neuroimage.2009.01.068.

de Frias, C. M., Dixon, R. A., Fisher, N., \& Camicioli, R. (2007). Intraindividual variability in neurocognitive speed: A comparison of Parkinson's disease and normal older adults. Neuropsychologia, 45, 2499-2507, doi:10.1016/j.neuropsychologia.2007.03.022.

de Frias, C. M., Lövdén, M., Lindenberger, U., \& Nilsson, L. G. (2007). Revisiting the dedifferentiation hypothesis with longitudinal multi-cohort data. Intelligence, 35, 381-392, doi:10.1016/j.intell.2006.07.011.

Düzel, S., Munte, T. F., Lindenberger, U., Bunzeck, N., Schutze, H., Heinze, H. J., et al. (2010). Basal forebrain integrity and cognitive memory profile in healthy aging. Brain Research, 1308, 124-136, doi:10.1016/j.brainres.2009.10.048.

Ekstrom, R. B., French, J. W., Harman, H. H., \& Derman, D. (1976). Manual for kit of factor-referenced cognitive tests. NJ: Educational Testing Service.

Elias, P. K., Elias, M. F., D’Agostino, R. B., Cupples, L. A., Wilson, P. W., Silbershatz, H., et al. (1997). NIDDM and blood pressure as risk factors for poor cognitive performance: The Framingham Study. Diabetes Care, 20, 1388-1395, doi:10.2337/diacare.20.9.1388.

Erixon-Lindroth, N., Farde, L., Wahlin, T. B., Sovago, J., Halldin, C., \& Bäckman, L. (2005). The role of the striatal dopamine transporter in cognitive aging. Psychiatry Research, 138, 1-12, doi:10.1016/j.pscychresns.2004.09.005.

Ezzyat, Y., \& Olson, I. R. (2008). The medial temporal lobe and visual working memory: Comparisons across tasks, delays, and visual similarity. Cognitive, Affective, E' Behavioral Neuroscience, 8, 32-40, doi:10.3758/CABN.8.1.32.

Feldt, L. S. (1961). The use of extreme groups to test for the presence of a relationship. Psychometrika, 26, 307-316, doi:10.1007/BF02289799.

Fisk, J. E., \& Sharp, C. A. (2003). The role of the executive system in visuo-spatial memory functioning. Brain and Cognition, 52, 364-381, doi:10.1016/ S0278-2626(03)00183-0.

Fjell, A. M., Walhovd, K. B., Reinvang, I., Lundervold, A., Dale, A. M., Quinn, B. T., et al (2005). Age does not increase rate of forgetting over weeks: Neuroanatomical volumes and visual memory across the adult life-span. Journal of the International Neuropsychological Society, 11, 2-15, doi:10.1017/S1355617705050046.

Fletcher, P. C., Shallice, T., \& Dolan, R. J. (1998). The functional roles of prefrontal cortex in episodic memory: I. Encoding. Brain, 121, 1239-1248, doi:10.1093/brain/121.7.1239.

Fletcher, P. C., Shallice, T., Frith, C. D., Frackowiak, R. S., \& Dolan, R. J. (1998). The functional roles of prefrontal cortex in episodic memory: II. Retrieval. Brain 121, 1249-1256, doi:10.1093/brain/121.7.1249.

Forbes, E. J., \& Reese, H. W. (1974). Pictorial elaboration and recall of multilist paired associates. Journal of Experimental Psychology, 102, 836-840, doi:10.1037/h0036364.

Frey, U., Huang, Y. Y., \& Kandel, E. R. (1993). Effects of cAMP simulate a late stage of LTP in hippocampal CA1 neurons. Science, 260, 1661-1664, doi:10.1126/science.8389057.

Gordon, B., \& Carson, K. (1990). The basis for choice reaction time slowing in Alzheimer's disease. Brain and Cognition, 13, 148-166, doi:10.1016 0278-2626(90)90047-R.

Gorus, E., De Raedt, R., Lambert, M., Lemper, J. C., \& Mets, T. (2008). Reaction times and performance variability in normal aging, mild cognitive impairment, and Alzheimer's disease. Journal of Geriatric Psychiatry and Neurology, 21, 204-218, doi:10.1177/0891988708320973.

Habeck, C., Rakitin, B. C., Moeller, J., Scarmeas, N., Zarahn, E., Brown, T., et al. (2004) An event-related fMRI study of the neurobehavioral impact of sleep deprivation on performance of a delayed-match-to-sample task. Cognitive Brain Research, 18, 306-321, doi:10.1016/j.cogbrainres.2003.10.019.

Hetherington, C. R., Stuss, D. T., \& Finlayson, M. A. J. (1996). Reaction time and variability 5 and 10 years after traumatic brain injury. Brain Injury, 10, 473-486, doi:10.1080/026990596124197.

Herlitz, A., Nilsson, L. G., \& Bäckman, L. (1997). Gender differences in episodic memory. Memory and Cognition, 25, 801-811, doi:10.1111/j.1467-8721. 2008.00547.x.

Hertzog, C., Dixon, R. A., Hultsch, D. F., \& MacDonald, S. W. S. (2003). Latent change models of adult cognition: Are changes in processing speed and working memory associated with changes in episodic memory? Psychology and Aging, 18, 755-769, doi:10.1037/0882-7974.18.4.755

Hofer, S. M., \& Sliwinski, M. J. (2001). Understanding ageing: An evaluation of research designs for assessing the interdependence of ageing-related changes. Gerontology, 47, 341-352, doi:10.1159/000052825.

Huang, Y. Y., \& Kandel, E. R. (1995). D1/D5 receptor agonists induce a protein synthesis-dependent late potentiation in the CA1 region of the hippocampus. Proceedings of the National Academy of Sciences of the United States of America, 92, 2446-2450. doi:10.1073/pnas.92.7.2446

Hultsch, D. F., MacDonald, S. W. S., Hunter, M. A., Levy-Bencheton, J., \& Strauss, E. (2000). Intraindividual variability in cognitive performance in older adults: Comparison of adults with mild dementia, adults with arthritis, and healthy adults. Neuropsychology, 14, 588-598, doi:10.1037/0894-4105. 14.4.588.

Huppert, F. A., \& Kopelman, M. D. (1989). Rates of forgetting in normal aging: A comparison with dementia. Neuropsychologia, 27, 849-860, doi:10.1016/0028-3932(89)90008-0. 
Kail, R. (1998). Speed of information processing in patients with multiple sclerosis. Journal of Clinical and Experimental Neuropsychology, 20, 98-106, doi:10.1076/jcen.20.1.98.1483.

Klein, C., Wendling, K., Huettner, P., Ruder, H., \& Peper, M. (2006). Intra-subject variability in attention-deficit hyperactivity disorder. Biological Psychiatry, 60, 1088-1097, doi:10.1016/j.biopsych.2006.04.003.

Kline, R. B. (2005). Principles and practice of structural equation modeling (2nd ed.). New York: Guilford Press.

Knotek, P. C., Bayles, K. A., \& Kaszniak, A. W. (1990). Response consistency on a semantic memory task in persons with dementia of the Alzheimer type. Brain and Language, 38, 465-475, doi:10.1016/0093-934X(90)90131-Y.

Kochunov, P., Coyle, T., Lancaster, J., Robin, D. A., Hardies, J., Kochunov, V., et al. (2010). Processing speed is correlated with cerebral health markers in the frontal lobes as quantified by neuroimaging. Neuroimage, 49, 1190-1199, doi:10.1016/j.neuroimage.2009.09.052.

Kopelman, M. D. (1985). Rates of forgetting in Alzheimer-type dementia and Korsakoff's syndrome. Neuropsychologia, 23, 623-638, doi:10.1016/0028-3932(85)90064-8.

Kopelman, M. D. (1992). Storage, forgetting and retrieval in the anterograde and retrograde amnesia of Alzheimer dementia. In L. Bäckman (Ed.), Memory functioning in dementia (pp. 45-71). Amsterdam: Elsevier Science Publishers.

Lang, P. J., Bradley, M. M., \& Cuthbert, B. N. (1997). International Affective Picture System (IAPS): Technical manual and affective ratings. Gainesville, FL: NIMH Center for the Study of Emotion and Attention, University of Florida.

Li, S. -C., Aggen, S. H., Nesselroade, J. R., \& Baltes, P. B. (2001). Short-term fluctuations in elderly people's sensorimotor functioning predict text and spatial memory performance: The MacArthur successful aging studies. Gerontology, 47, 100-116, doi:10.1159/000052782.

Li, S. -C., Brehmer, Y., Shing, Y. L., Werkle-Bergner, M., \& Lindenberger, U. (2006). Neuromodulation of associative and organizational plasticity across the lifespan: Empirical evidence and neurocomputational modeling. Neuroscience and Biobehavioral Reviews, 30, 775-790, doi:10.1016/j.neubiorev.2006.06.004.

Li, S. -C., Chicherio, C., Nyberg, L., von Oertzen, T., Nagel, I. E., Papenberg, G., et al. (2010). Ebbinghaus revisited: Influences of the BDNF Val66Met polymorphism on backward serial recall are modulated by human aging. Journal of Cognitive Neuroscience, 10, 2164-2173, doi:10.1162/jocn.2009.21374.

Li, S. -C., Hämmerer, D., Müller, V., Hommel, B., \& Lindenberger, U. (2009). Lifespan development of stimulus-response conflict cost: Similarities and differences between maturation and senescence. Psychological Research, 73, 777-785, doi:10.1007/s00426-008-0190-2.

Li, S. -C., \& Lindenberger, U. (1999). Cross-level unification: A computational exploration of the link between deterioration of neurotransmitter systems and dedifferentiation of cognitive abilities in old age. In L. -G. Nilsson, \& H. Markowitsch (Eds.), Cognitive neuroscience of memory (pp. 103-146). Seattle: Hogrefe \& Huber.

Li, S. -C., Lindenberger, U., Hommel, B., Aschersleben, G., Prinz, W., \& Baltes, P. B. (2004). Transformations in the couplings among intellectual abilities and constituent cognitive processes across the life span. Psychological Science, 15, 155-163, doi:10.1111/j.0956-7976.2004.01503003.x.

Li, S. -C., Lindenberger, U., \& Sikström, S. (2001). Aging cognition: From neuromodulation to representation. Trends in Cognitive Sciences, 5, 479-486, doi:10.1016/S1364-6613(00)01769-1.

Li, S. -C., \& Sikström, S. (2002). Integrative neurocomputational perspectives on cognitive aging, neuromodulation, and representation. Neuroscience and Biobehavioral Reviews, 26, 795-808, doi:10. 1016/S0149-7634(02) 00066- 0.

Lindenberger, U., \& Baltes, P. B. (1994). Sensory functioning and intelligence in old age: A strong connection. Psychology and Aging, 9, 339-355, doi:10.1037/0882-7974.9.3.339.

Lindenberger, U., Mayr, U., \& Kliegl, R. (1993). Speed and intelligence in old age. Psychology and Aging, 8, 207-220, doi:10.1037/0882-7974.8.2.207.

Lisman, J. E., \& Grace, A. A. (2005). The hippocampal-VTA loop: Controlling the entry of information into long-term memory. Neuron, 46, 703-713, doi:10.1016/j.neuron.2005.05.002.

Lövdén, M., Li, S. -C., Shing, Y. L., \& Lindenberger, U. (2007). Within-person trial-to-trial variability precedes and predicts cognitive decline in old and very old age: Longitudinal data from the Berlin Aging Study. Neuropsychologia, 45, 2827-2838, doi:10.1016/j.neuropsychologia.2007.05.005.

MacDonald, S. W. S., Cervenka, S., Farde, L., Nyberg, L., \& Bäckman, L. (2009). Extrastriatal dopamine D2 receptor binding modulates intraindividual variability in episodic recognition and executive functioning. Neuropsychologia, 47, 2299-2304, doi:10.1016/j.neuropsychologia.2009.01.016

MacDonald, S. W. S., Hultsch, D. F., \& Dixon, R. A. (2003). Performance variability is related to change in cognition: Evidence from the Victoria Longitudinal Study. Psychology and Aging, 18, 510-523, doi:10.1037/0882-7974.18.3.510.

MacDonald, S. W. S., Li, S. -C., \& Bäckman, L. (2009). Neural underpinnings of within-person variability in cognitive functioning. Psychology and Aging, 4, 792-808, doi: $10.1037 / \mathrm{a} 0017798$.

MacDonald, S. W. S., Nyberg, L., \& Bäckman, L. (2006). Intra-individual variability in behavior: Links to brain structure, neurotransmission and neuronal activity. Trends in Neurosciences, 29, 474-480, doi:10.1016/j.tins.2006.06.011.

MacDonald, S. W. S., Nyberg, L., Sandblom, J., Fischer, H., \& Bäckman, L. (2008). Increased response-time variability is associated with reduced inferior parietal activation in recognition memory in aging. Journal of Cognitive Neuroscience, 20 , 779-786, doi:10.1162/jocn.2008.20502.

MacDonald, S. W. S., Stigsdotter-Neely, A., Derwinger, A., \& Bäckman, L. (2006). Rate of acquisition, adult age, and basic cognitive abilities predict forgetting:
New views on a classic problem. Journal of Experimental Psychology-General, 135, 368-390, doi:10.1037/0096-3445.135.3.368.

Macmillan, N. A, \& Creelman, C. D. (2005). Detection theory: A user's guide (2nd ed.). Mahwah, NJ: Lawrence Erlbaum Associates.

Madden, D. J., Bennett, I. J., \& Song, A. W. (2009). Cerebral white matter integrity and cognitive aging: Contributions from diffusion tensor imaging. Neuropsychology Review, 19, 415-435, doi:10.1007/s11065-009-9113-2.

Manoach, D. S. (2003). Prefrontal cortex dysfunction during working memory performance in schizophrenia: Reconciling discrepant findings. Schizophrenia Research, 60, 285-298, doi:10.1016/S0920-9964(02)00294-3.

Manoach, D. S., Gollub, R. L., Benson, E. S., Searl, M. M., Goff, D. C., Halpern, E. et al. (2000). Schizophrenic subjects show aberrant fMRI activation of dorsolateral prefrontal cortex and basal ganglia during working memory performance. Biological Psychiatry, 48, 99-109, doi:10.1016/S0006-3223(00)00227-4.

McKee, R. D., \& Squire, L. R. (1992). Equivalent forgetting rates in long-term memory for diencephalic and medial temporal lobe amnesia. Journal of Neuroscience, 12, 3765-3772. PMid:1403083.

McNab, F., Varrone, A., Farde, L., Jucaite, A., Bystritsky, P., Forssberg, H., et al. (2009). Changes in cortical dopamine D1 receptor binding associated with cognitive training. Science, 323, 800-802, doi:10.1126/science.1166102.

Meredith, W. (1964). Notes on factorial invariance. Psychometrika, 29, 177-185, doi:10.1007/BF02289699.

Murtha, S., Cismaru, R., Waechter, R., \& Chertkow H. (2002). Increased variability accompanies frontal lobe damage in dementia. Journal of the International Neuropsychological Society, 8, 360-372, doi:10.1017/S1355617702813170.

Nagel, I. E., Chicherio, C., Li, S. -C., von Oertzen, T., Sander, T., Villringer, A., et al. (2008). Human aging magnifies genetic effects on executive functioning and working memory. Frontiers in Human Neuroscience, 2, 1-8, doi:10.3389/neuro.09.001.2008.

Nyberg, L., Andresson, M., Jakobsson-Mo, S., Larsson, A., Marklund, P., Riklund, K., et al.(2009). Striatal dopamine D2 binding is related to frontal bold response during updating of long-term memory representations. Neuroimage, 46, 1194-1199, doi:10.1016/j.neuroimage.2009.03.035.

O'Carroll, C. M., Martin, S. J., Sandin, J., Frenguelli, B., \& Morris, R. G. M. (2006). Dopaminergic modulation of the persistence of one-trial hippocampus-dependent memory. Learning \& Memory, 13, 760-769, doi:10.1101/lm.321006.

Oldfield, R. C. (1971). The assessment and analysis of handedness: The Edinburgh inventory. Neuropsychologia, 9, 97-113, doi:10.1016/0028-3932(71)90067-4.

Park, D. C., Royal, D., Dudley, W., \& Morrell, R. (1988). Forgetting of pictures over a long retention interval in young and older adults. Psychology and Aging, 3, 94-95, doi:10.1037/0882-7974.3.1.94.

Park, D. C., Welsh, R. C., Marshuetz, C., Gutchess, A. H., Mikels, J., Polk, T. A. et al. (2003). Working memory for complex scenes: Age differences in frontal and hippocampal activations. Journal of Cognitive Neuroscience, 15, 1122-1134, doi:10.1162/089892903322598094.

Piekema, C., Fernandez, G., Postma, A., Hendriks, M. P., Wester, A. J., \& Kessels, R. P. (2007). Spatial and non-spatial contextual working memory in patients with diencephalic or hippocampal dysfunction. Brain Research, 1172, 103-109, doi:10.1016/j.brainres.2007.07.066.

Preacher, K. J., Rucker, D. D., MacCallum, R. C., \& Nicewander, W. A. (2005). Use of the extreme groups approach: A critical reexamination and new recommendations. Psychological Methods, 10, 178-192, doi:10.1037/1082-989X.10.2.178.

Ram, N., Rabbitt, P., Stollery, B., \& Nesselroade, J. R. (2005). Cognitive performance inconsistency: Intraindividual change and variability. Psychology and Aging, 20, 623-633, doi:10.1037/0882-7974. 20.4.623.

Rabbitt, P., Osman, P., Moore, B., \& Stollery, B. (2001). There are stable individual differences in performance variability, both from moment to moment and from day to day. Quarterly Journal of Experimental Psychology Section A, 54, 981-1003, doi:10.1080/02724980042000534.

Raz, N., Dahle, C. L., Rodrigue, K. M., Kennedy, K. M., Land, S. J., \& Jacobs, B. S. (2008). Brain-derived neurotrophic factor Val66Met and blood glucose: A synergistic effect on memory. Frontiers in Human Neuroscience, 2, 1-6, doi:10.3389/neuro.09.012.2008.

Raz, N., Rodrigue, K. M., Kennedy, K. M., \& Land, S. (2009). Genetic and vascular modifiers of age-sensitive cognitive skills: Effects of COMT, BDNF, ApoE, and hypertension. Neuropsychology, 23, 105-116, doi:10.1037/a0013487.

Richardson, J. T. (2007). Measures of short-term memory: A historical review. Cortex, 43, 635-650, doi:10.1016/S0010-9452(08)70493-3.

Rogosa, D., Brandt, D., \& Zimowski, M. (1982). A growth curve approach to the measurement of change. Psychological Bulletin, 92, 726-748, doi:10.1037/0033-2909.92.3.726.

Rossato, J. I., Bevilaqua, L. R. M., Izquierdo, I., Medina, J. H., \& Cammarota, M. (2009). Dopamine controls persistence of long-term memory storage. Science, 325, 1017-1020, doi:10.1126/science. 1172545.

Rudkin, S. J., Pearson, D. G., \& Logie, R. H. (2007). Executive processes in visual and spatial working memory tasks. Quarterly Journal of Experimental Psychology, 60, 79-100, doi:10.1080/17470210600587976.

Rybarczyk, B. D., Hart, R. P., \& Harkins, S. W. (1987). Age and forgetting rate with pictorial stimuli. Psychology and Aging, 2, 404-406, doi:10.1037/0882-7974. 2.4.404.

Salthouse, T. A. (1996). The processing-speed theory of adult age differences in cognition. Psychological Review, 103, 403-428, doi:10.1037/0033-295X.103.3.403.

Sawaguchi, T., \& Goldman-Rakic, P. S. (1991). D1 dopamine receptors in prefrontal cortex: Involvement in working memory. Science, 251, 947-950, doi: $10.1126 /$ science. 1825731 . 
Schaie, K. W., Maitland, S. B., Willis, S. L., \& Intrieri, R. C. (1998). Longitudinal invariance of adult psychometric ability factor structures across 7 years. Psychology and Aging, 13, 8-20, doi:10.1037/0882-7974.13.1.8.

Schmiedek, F., Lövdén, M., \& Lindenberger, U. (2009). On the relation of mean reaction time and intraindividual reaction time variability. Psychology and Aging, 24, 841-857, doi:10.1037/a0017799.

Schott, B. H., Seidenbecher, C. I., Fenker, D. B., Lauer, C. J., Bunzeck, N., Bernstein H. -G., et al. (2006). The dopaminergic midbrain participates in human episodic memory formation: Evidence from genetic imaging. Journal of Neuroscience, 26, 1407-1417, doi:10.1523/jneurosci.3463-05.2006.

Servan-Schreiber, D., Printz, H., \& Cohen, J. D. (1990). A network model of catecholamine effects: Gain, signal-to-noise ratio, and behavior. Science, 249, 892-895, doi:10.1126/science.2392679.

Shammi, P., Bosman, E., \& Stuss, D. T. (1998). Aging and variability in performance. Aging, Neuropsychology, and Cognition, 5, 1-13, doi:10.1076/anec.5.1.1.23.

Slamecka, N. J., \& McElree, B. (1983). Normal forgetting of verbal lists as a function of their degree of learning. Journal of Experimental Psychology: Learning, Memory, and Cognition, 9, 384-397, doi:10.1037/0278-7393.9.3.384.

Sliwinski, M. J., Smyth, J. M., Hofer, S. M., \& Stawski, R. S. (2006). Intraindividual coupling of daily stress and cognition. Psychology and Aging, 21, 545-557, doi:10.1037/0882-7974.21.3.545.

Smith, E. E., \& Jonides, J. (1999). Storage and executive processes in the frontal lobes. Science, 283, 1657-1661, doi:10.1126/science.283.5408.1657.

Spikman, J. M., Berg, I. J., \& Deelman, B. G. (1995). Spared recognition capacity in elderly and closed-head-injury subjects with clinical memory deficits. Journal of Clinical and Experimental Neuropsychology, 17, 29-34, doi:10.1080/13803399508406578.

Stefanis, N. C., van Os, J., Avramopoulos, D., Smyrnis, N., Evdokimidis, I., \& Stefanis, C. N. (2005). Effect of COMT Val(158)Met polymorphism on the continuous performance test, identical pairs version: Tuning rather than improving performance. American Journal of Psychiatry, 162, 1752-1754, doi:10.1176/appi.ajp.162.9.1752.

Strauss, E., Bielak, A. A. M., Bunce, D., Hunter, M. A., \& Hultsch, D. F. (2007). Within-person variability in response speed as an indicator of cognitive impairment in older adults. Aging, Neuropsychology, and Cognition, 14, 608-630, doi:10.1080/13825580600932419.

Stuss, D. T., Murphy, K. J., Binns, M. A., \& Alexander, M. P. (2003). Staying on the job: The frontal lobes control individual performance variability. Brain: A Journal of Neurology, 126, 2363-2380, doi:10.1093/brain/awg237.
Squire, L. R., Stark, C. E. L., \& Clark, R. E. (2004). The medial temporal lobe. Annual Review of Neuroscience, 27, 279-306, doi:10.1146/annurev.neuro. 27.070203.144130.

Takahashi, H., Kato, M., Hayashi, M., Okubo, Y., Takano, A., Ito, H., et al (2007). Memory and frontal lobe functions; possible relations with dopamine D2 receptors in the hippocampus. Neuroimage, 34, 1643-1649, doi:10.1016/j.neuroimage.2006.11.008.

Takahashi, H., Kato, M., Takano, H., Arakawa, R., Okumura, M., Otsuka, T., et al (2008). Differential contributions of prefrontal and hippocampal dopamine $\mathrm{D}(1)$ and $\mathrm{D}(2)$ receptors in human cognitive functions. Journal of Neuroscience, 28 12032-12038, doi:10.1523/jneurosci.3446-08.2008.

Underwood, B. J., \& Richardson, J. (1956). The influence of meaningfulness, intralist similarity, and serial position on retention. Journal of Experimental Psychology 52, 119-126, doi:10.1037/h0045452.

Vaurio, R. G, Simmonds, D. J., \& Mostofsky, S. H. (2009). Increased intra-individua reaction time variability in attention-deficit/hyperactivity disorder across response inhibition tasks with different cognitive demands. Neuropsychologia 47, 2389-2396, doi:10.1016/j.neuropsychologia.2009.01.022.

Volkow, N. D., Gur, R. C., Wang, G. J., Fowler, J. S., Moberg, P. J., Ding, Y. S., et al. (1998) Association between decline in brain dopamine activity with age and cognitive and motor impairment in healthy individuals. American Journal of Psychiatry, 155, 344-349. PMid:9501743.

Walhovd, K. B., \& Fjell, A. M. (2007). White matter volume predicts reaction time instability. Neuropsychologia, 45, 2277-2284, doi:10.1016/j.neuropsychologia. 2007.02.022.

Winterer, G., \& Weinberger, D. R. (2004). Genes, dopamine and cortica signal-to-noise ratio in schizophrenia. Trends in Neurosciences, 27, 683-690 doi:10.1016/j.tins.2004.08.002.

Wittmann, B. C., Schott, B. H., Guderian, S., Frey, J. U., Heinze, H. J., \& Düzel, E. (2005) Reward-related fMRI activation of dopaminergic midbrain is associated with enhanced hippocampus-dependent long-term memory formation. Neuron, 45 459-467, doi:10.1016/j.neuron.2005.01.010.

Williams, B. R., Hultsch, D. F., Strauss, E. H., Hunter, M. A., \& Tannock, R. (2005) Inconsistency in reaction time across the life span. Neuropsychology, 19, 88-96 doi:10.1037/0894-4105.19.1.88.

World Health Organization, International Society of Hypertension Writing Group. (2003). 2003 World Health Organization (WHO)/International Society of Hypertension (ISH) statement on management of hypertension. Journal of Hypertension, 21, 1983-1992. PMID: 14597836. 